\title{
Viabilidade de inserção dos efeitos da uniformidade de irrigação em modelos de crescimento de culturas
}

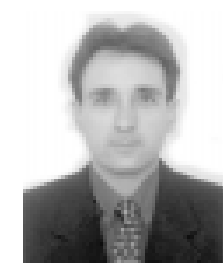

Paulo S. L. de Freitas ${ }^{1}$, Roberto Rezende ${ }^{2}$, Everardo C. Mantovani ${ }^{3}$ \& José A. Frizzone ${ }^{4}$

\author{
1 DAG, Univ. Est. de Maringá. Av. Colombo 5790, CEP 87020-900, Maringá, PR. E-mail: pslfreitas@uem.br (Foto) \\ 2 DAG, Universidade Estadual de Maringá. CEP 87020-900, Maringá, PR. E-mail: rrezende@uem.br \\ ${ }^{3}$ DEA/UFV. Av. P.H. Rolfs s/n, CEP 36571-000,Viçosa, MG. E-mail: everardo@ufv.br \\ 4 DER/ESALQ/USP, Piracicaba, SP. E-mail: frizzone@carpa.ciagri.usp.br
}

Protocolo $90-1 / 7 / 2002$ - Aprovado em 24/9/2003

\begin{abstract}
Resumo: Os experimentos que compõem o presente estudo, foram conduzidos para as culturas do milho e do feijão, ensejando a avaliação do efeito da uniformidade de aplicação de água na produção das culturas. Para cultura do milho, os tratamentos constaram de cinco lâminas de irrigação e duas uniformidades de aplicação, uma alta (CUC > 82\%) e outra baixa (CUC < $67 \%$ ) e, no feijão, de quatro uniformidades de aplicação de água (CUC - 94,1, 85,6, 65,6 e $57,9 \%)$. Ajustou-se uma equação de regressão para os valores da produtividade da cultura do milho em função da lâmina d'água, para os tratamentos com alta uniformidade, enquanto para os de baixa uniformidade na cultura do milho e para todos os tratamentos na cultura do feijão não foi possível ajuste, observando-se baixos valores de $\mathrm{R}^{2}$. Estas informações indicam que é impossível a incorporação do efeito da uniformidade de aplicação nos modelos de simulação de crescimento de culturas.
\end{abstract}

Palavras-chave: uniformidade de aplicação, cultura do milho e do feijão, modelos de simulação de crescimento, CUC

\section{Viability of introducing the effects of irrigation uniformity in crop growth models}

\begin{abstract}
A study was designed to evaluate the effects of uniformity of sprinkler irrigation in maize and dry bean crops. For maize crop, the treatments consisted of five depths of water applied in two application uniformities: one high (CUC $>82 \%$ ) and the other low (CUC $<67 \%$ ). For dry beans, the treatments consisted of four Christiansen application uniformity coefficients (CUC - 94.1, 85.6, 65.6 and 57.9\%). A regression equation was adjusted for maize grain yield versus water application depth for high uniformity irrigation treatments, whereas for treatments with low irrigation uniformity in maize crop and for all treatments in dry beans the regression equations observed had very low values of $R^{2}$. These data indicate that, it is impossible to introduce irrigation uniformity effects in crop growth simulation models
\end{abstract}

Key words: irrigation uniformity, maize crop, dry bean, simulation models, CUC

\section{INTRODUÇÃO}

A água é um dos principais fatores de produção na agricultura, e cada espécie de planta necessita de um adequado nível de água no solo para que suas necessidades fisiológicas sejam atendidas. Se a quantidade de água aplicada na irrigação das culturas determinada pelo critério da maximização de lucros, em detrimento da maximização da produção, for utilizada considerável quantidade de água poderia ser economizada (Letey et al., 1984). Nenhum sistema de irrigação é capaz de aplicar água com perfeita uniformidade e, para aumentar o grau da uniformidade de aplicação, são necessários investimentos para aquisição de sistemas mais eficientes ou para adequação do sistema existente e, ainda, para cobrir o custo de mão-deobra, para o manejo de irrigação.

Quando o fator água não é limitante, tem-se compensado a desuniformidade de aplicação de água utilizando-se quantidades superiores às necessárias se a aplicação fosse uniforme, com o objetivo de permitir que apenas pequenas áreas do campo apresentem deficit hídrico (Walker, 1979).

Alguma desuniformidade de aplicação de água deve ser tolerada para os sistemas de irrigação. Vários autores (Howell, 1964; Walker, 1979; von Bermuth, 1983; Clemens, 1988; Duke et al., 1992; Rezende et al., 1998) avaliaram a relação entre a uniformidade de aplicação de água e os parâmetros de desempenho de sistemas de irrigação, ou variabilidade da produtividade das culturas. 
Mateos et al. (1997) avaliaram a resposta da cultura do algodão à desuniformidade de aplicação de água e a duas lâminas de irrigação. No tratamento de reposição total da lâmina foram aplicados 400 e $260 \mathrm{~mm}$ de água, tendo os coeficientes de uniformidade de Wilkox \& Swailes sido de 90 e 67\%, para alta e baixa uniformidade, respectivamente; no entanto, não houve diferença significativa entre os tratamentos de lâmina e o coeficiente de uniformidade, quando analisaram a produtividade da cultura, que foi, em média, de $2.349 \mathrm{~kg} \mathrm{ha}^{-1}$.

A influência da uniformidade de irrigação de água na produtividade das culturas e na lixiviação de nitrogênio foi avaliada por Pang et al. (1997) com uso do modelo CERESMaize. Para introduzir o efeito da uniformidade de aplicação de água na produtividade, os autores utilizaram a metodologia proposta por Letey et al. (1984). As simulações foram realizadas para os níveis de uniformidade de aplicação, isto é, para o coeficiente de uniformidade de Christiansen (CUC) de 100, $90 \mathrm{e}$ $75 \%$ e dois níveis de aplicação de nitrogênio 180 e $240 \mathrm{~kg} \mathrm{ha}^{-1}$. Não ocorreu diferença de produtividade entre os tratamentos com a uniformidade de aplicação de água de 90 e $100 \%$, porém a produtividade foi menor para o tratamento de CUC de $75 \%$.

Os modelos de crescimento de culturas apresentam potencial de uso para responder questões em pesquisa, manejo de culturas e planejamento, auxiliando no entendimento sobre as interações genéticas, fisiológicas e do ambiente, como também nas decisões de práticas culturais antes e durante o período da cultura no campo, como aplicações de fertilizantes e irrigação (Boote et al., 1996).

O modelo CERES-Maize está agrupado em um Sistema de Suporte à Decisão para Transferência de Tecnologia (DSSAT) e tem sido amplamente utilizado em todo o mundo. Ele considera o processo do balanço de água no solo, a interceptação da radiação pelo dossel, a produção de matéria seca e a partição da biomassa (Kiniry et al., 1997).

O CERES-Maize e BEANGRO, apesar de suas complexidades, não consideram o efeito da uniformidade de aplicação de água nos componentes de produção da cultura do milho. Alguns autores desenvolveram modelos empíricos nos quais o efeito da uniformidade de aplicação de água nos componentes de produção é considerado (Seginer, 1978; Letey et al., 1984; Mantovani et al., 1995; Li, 1998).

Com o presente trabalho, objetivou-se obter informações para introduzir em modelos de simulação de crescimento de culturas, o efeito da uniformidade de aplicação de água de sistema de irrigação por aspersão, usando cultura do milho e do feijão.

\section{MATERIAL E MÉTODOS}

Os experimentos foram conduzidos em duas localidades: Coimbra, MG, com a cultura do milho, e em Maringá, PR, com a cultura do feijão.

$\mathrm{O}$ experimento com a cultura do milho foi conduzido na Estação Experimental de Coimbra, do Departamento de Fitotecnia da Universidade Federal de Viçosa, no ano de 1999, cujas coordenadas geográficas são: latitude de $20^{\circ} 51^{\prime} \mathrm{S}$, longitude de $42^{\circ} 47^{\prime} \mathrm{W}$ e altitude de $720 \mathrm{~m}$, em solo do tipo Argissolo Vermelho-Amarelo Câmbico.
A semeadura foi realizada no dia 17 de maio de 1999, tendo sido utilizado cultivar BR 201, com espaçamento entre as linhas de $100 \mathrm{~cm}$ e de $20 \mathrm{~cm}$ entre as plantas, totalizando 50.000 plantas por hectare e a colheita do experimento foi realizada a partir do dia 23 de novembro de 1999, época em que a cultura atingiu a maturidade fisiológica. O índice de área foliar (IAF) foi medido após o florescimento da cultura.

Para realização das análises dos parâmetros físico-hídricos do solo, como densidade do solo e granulometria, foram retiradas amostras a cada $20 \mathrm{~cm}$, até a profundidade de $80 \mathrm{~cm}$.

O limite superior de água no solo foi determinado em campo, utilizando-se a metodologia descrita por Bernardo (1995). Os valores obtidos foram de 0,426 e $0,45 \mathrm{~m}^{3} \mathrm{~m}^{-3}$, para as camadas de 0-20 e 20-40 cm, respectivamente, e o limite inferior de água disponível foi assumido como sendo umidade correspondente a $-1500 \mathrm{kPa}$. Os valores obtidos foram 0,30 e $0,32 \mathrm{~m}^{3} \mathrm{~m}^{-3}$, respectivamente.

$\mathrm{O}$ experimento de campo foi instalado de acordo com o esquema apresentado na Figura 1. O delineamento experimental foi em blocos ao acaso, e os tratamentos constaram de lâminas d'água e de uniformidades de irrigação (CUC): alta (>82\%) e baixa $(<67 \%)$, para os tratamentos com alta uniformidade de aplicação foram cinco lâminas e para os de baixa uniformidade foram três lâminas, sendo, para essa condição, a maior lâmina foi igual a necessária para suprir o défice hídrico, com 50\% de área adequadamente irrigada, que de acordo com Walker (1979) as aplicações de lâmina superiores a requerida poderiam reduzir área de défice, comprometer os tratamentos com aplicações de água com baixa uniformidade. As parcelas apresentaram dimensões de $12 \mathrm{~m}$ de largura e $36 \mathrm{~m}$ de comprimento. Os dados para a análise foram obtidos em áreas em torno dos coletores instalados nas parcelas, com o objetivo de se analisar a influência da água aplicada nos componentes de produção da cultura. No tratamento denominado $\mathrm{L}_{1} \mathrm{~A}$, aplicou-se uma lâmina d'água suficiente para elevar a umidade do solo, determinada antes da irrigação, até atingir o limite superior de água no solo. A lâmina d'água aplicada no tratamento $\mathrm{L}_{1} \mathrm{~A}$ será, doravante, denominada lâmina d'água adequada. As lâminas aplicadas nos demais tratamentos foram relativas ao tratamento $\mathrm{L}_{1} \mathrm{~A}$. Nos tratamentos $\mathrm{L}_{2} \mathrm{~A}, \mathrm{~L}_{3} \mathrm{~A}, \mathrm{~L}_{4} \mathrm{~A}$ e $\mathrm{L}_{5} \mathrm{~A}$ foram aplicados, respectivamente, 50,75, 125 e $150 \%$ da lâmina adequada, com uniformidade maior que $82 \%$. $\mathrm{L}_{2} \mathrm{~B}, \mathrm{~L}_{3} \mathrm{~B}$ e $\mathrm{L}_{1} \mathrm{~B}$ correspondem a 50,75 e $100 \%$, respectivamente, da lâmina aplicada $\mathrm{em}_{1} \mathrm{~A}$, com uniformidade menor que $67 \%$.

Para análise dos dados de produtividade e IAF (índice de área foliar) foram utilizados os dados obtidos em 81 áreas, com cinco plantas de milho, em torno dos coletores instalados nos tratamentos com alta uniformidade de aplicação; o mesmo procedimento foi utilizado para os tratamentos de baixa uniformidade.

Para análise de regressão, ajustou-se um modelo quadrático, obtendo-se os valores de significância para os coeficientes de regressão a 5\%, pelo teste t.

O modelo adotado foi:

$$
\mathrm{Y}=\mathrm{B}_{0}+\mathrm{B}_{1} \mathrm{~L}+\mathrm{B}_{2} \mathrm{~L}^{2}+\mathrm{B}_{3} \mathrm{CUC}+\mathrm{B}_{4} \mathrm{CUC}^{2}
$$




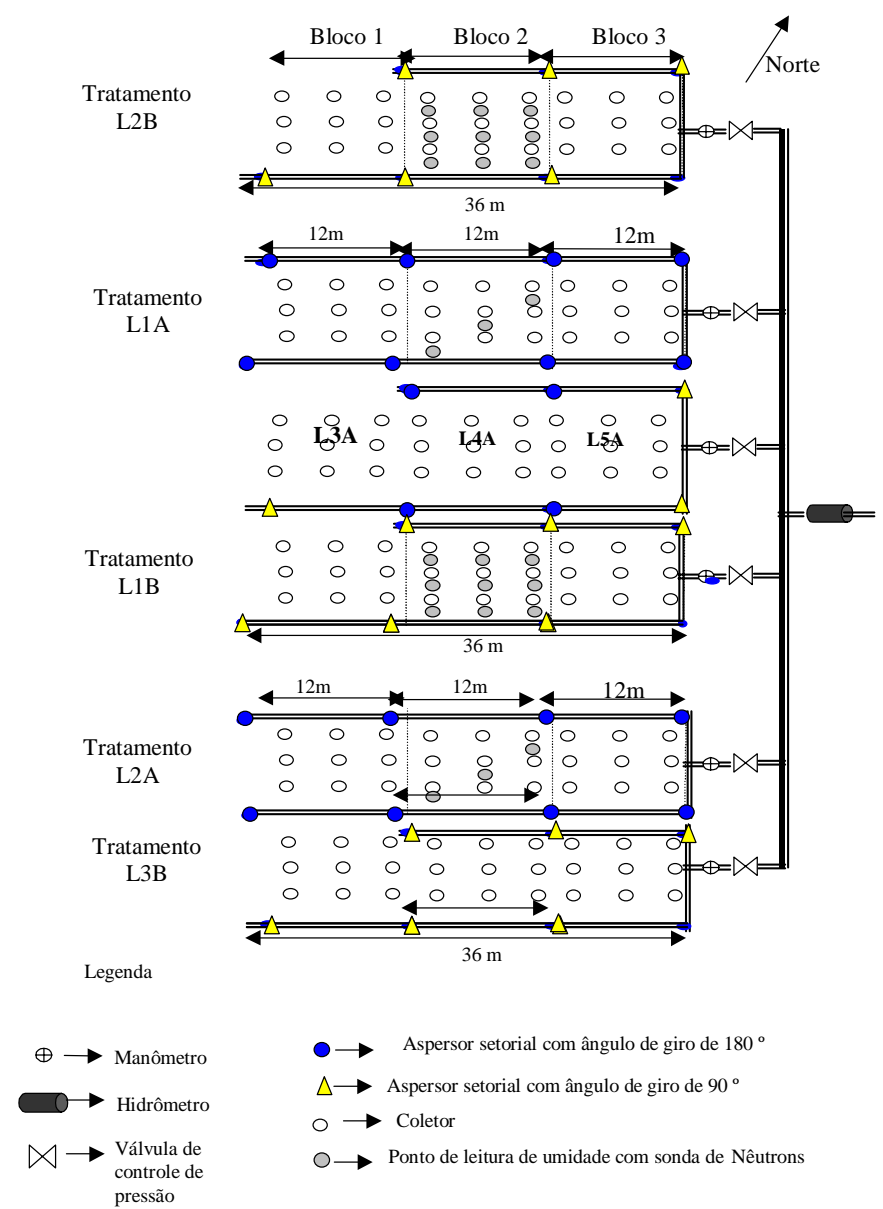

Figura 1. Esquema do experimento e sistema de irrigação instalado na área experimental de Coimbra, MG

em que:

Y - produtividades, $\mathrm{kg} \mathrm{ha}^{-1}$

L - lâmina de água, $\mathrm{mm}$

CUC - coeficiente de uniformidade de Christiansen, \%

$\mathrm{B}_{0}, \mathrm{~B}_{1}, \mathrm{~B}_{2}, \mathrm{~B}_{3}$ e $\mathrm{B}_{4}$ - coeficientes da regressão

Nos tratamentos de alta uniformidade, os aspersores foram dispostos nos quatro extremos da parcela, com um ângulo de giro do aspersor de $180^{\circ}$, e nos de baixa uniformidade estes foram colocados em uma das diagonais da parcela, com ângulo de giro de $90^{\circ}$. Para se obter a uniformidade de irrigação em torno de $67 \%$, foi necessário atuar no deflector do jato de água do aspersor, com o objetivo de fracionar o jato para que o seu alcance, em um dos aspersores, fosse reduzido, a fim de que ele atingisse apenas um número de coletores da parcela, enquanto o jato de água do outro aspersor, localizado na diagonal oposta, atingisse os demais coletores. Desta forma, os coletores próximos ao aspersor, com deflector ajustado, recebiam lâminas de água superiores às dos demais.

$\mathrm{Na}$ irrigação seguinte, retornou-se o deflector do aspersor para a posição normal e se ajustou o deflector do aspersor da diagonal oposta, fazendo com que a cada duas irrigações, determinadas áreas dentro da parcela recebessem uma lâmina muito superior à adequada. Foram utilizados aspersores da marca NAAN, modelo 427, setorial, com bocal de 3,5 mm e com pressão de serviço de $285 \mathrm{kPa}$; nestas condições, o aspersor apresentava uma vazão de $0,68 \mathrm{~m}^{3} \mathrm{~h}^{-1}$.
As irrigações foram realizadas semanalmente, antes do amanhecer, por causa dos fortes ventos ocorridos no local. A lâmina a ser reposta ao solo foi calculada mediante o uso da umidade média obtida em três pontos, por meio de tubos de acesso instalados na parcela $\mathrm{L}_{1} \mathrm{~A}$, nas camadas de 0-20, 20-40, 40-60 e 60-80 cm. Em todas as parcelas foram instalados tubos de acesso da sonda e, nos tratamentos de alta uniformidade, três tubos na diagonal da parcela, enquanto nos tratamentos de baixa uniformidade foram instalados nove tubos de acesso. A profundidade radicular da cultura foi estimada com o uso do perfil de extração de água pela cultura do milho, estimada a partir das medições de umidade do solo por meio da sonda de nêutrons.

A umidade do solo foi determinada no final do dia anterior às irrigações, a partir das leituras realizadas com uma sonda de nêutrons, modelo CPN 503, nos pontos com os tubos de acesso (Figura 1); já em relação à lâmina bruta aplicada, calculada mediante o uso da eficiência potencial de aplicação, para o tratamento $\mathrm{L}_{1} \mathrm{~A}$, estimada a partir de irrigações realizadas anteriormente para condições aproximadas ao horário das irrigações. Deste valor calculou-se a lâmina bruta a ser aplicada e que era monitorada por meio de hidrômetro, instalado na tubulação principal (Figura 1), previamente calibrado em laboratório.

A pressão foi medida com um manômetro metálico, cuja escala de medida variava de 0 a $475 \mathrm{kPa}$, instalado na entrada da linha lateral. A pressão foi regulada por meio de uma válvula de gaveta instalada na entrada da parcela. $\mathrm{O}$ volume aplicado foi calculado a partir da lâmina de água a ser reposta ao solo, em cada tratamento, e era função do porcentual da lâmina d'água a ser aplicada no tratamento $\mathrm{L}_{1} \mathrm{~A}$. Após atingir o volume aplicado nos tratamentos de menor lâmina de água, isto é, $\mathrm{L}_{2} \mathrm{~A}$ e $\mathrm{L}_{2} \mathrm{~B}$, que corresponde a $50 \%$ da lâmina de água do tratamento $\mathrm{L}_{1} \mathrm{~A}$, fechou-se a válvula de gaveta e o volume foi novamente calculado, para completar a irrigação nos outros tratamentos.

As lâminas de água totais aplicadas na cultura do milho em cada tratamento ao longo do ciclo da cultura, estão apresentadas na Tabela 1. Foram realizadas 26 irrigações semanais. As precipitações pluviais ocorridas durante o ciclo da cultura (Figura 2) não afetaram os resultados do experimento, pois

Tabela 1. Lâmina total aplicada nos experimentos com a cultura do milho

\begin{tabular}{ccccccccc}
\hline Tratamento & $\mathrm{L}_{1} \mathrm{~A}$ & $\mathrm{~L}_{2} \mathrm{~A}$ & $\mathrm{~L}_{3} \mathrm{~A}$ & $\mathrm{~L}_{4} \mathrm{~A}$ & $\mathrm{~L}_{5} \mathrm{~A}$ & $\mathrm{~L}_{1} \mathrm{~B}$ & $\mathrm{~L}_{2} \mathrm{~B}$ & $\mathrm{~L}_{3} \mathrm{~B}$ \\
\hline Lâmina & 352,4 & 235,5 & 309,2 & 415,8 & 489,4 & 319,1 & 204,3 & 259,6 \\
\hline
\end{tabular}

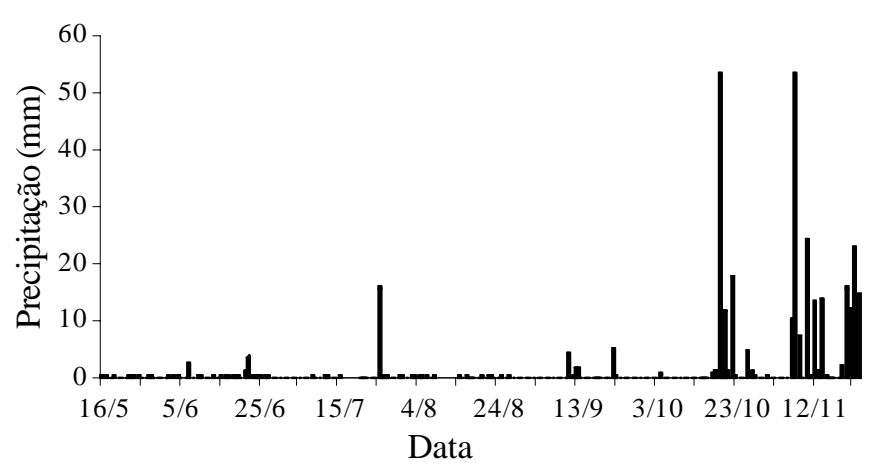

Figura 2. Precipitação durante o ciclo da cultura 
elas se concentraram na época em que os grãos estavam na fase do farináceo. O total precipitado durante o ciclo da cultura foi de $265 \mathrm{~mm}$.

$\mathrm{Na}$ área experimental de irrigação do Departamento de Agronomia da Universidade Estadual de Maringá, no município de Maringá, Paraná, localizada geograficamente a latitude de $23^{\circ} 25^{\prime} \mathrm{S}$ e a longitude $51^{\circ} 57^{\prime} \mathrm{W}$, com altitude média de $542 \mathrm{~m}$, foi conduzido, outro experimento, onde cultivou-se o feijão, sendo o mesmo realizado no primeiro semestre de 1998.

O solo da área experimental foi classificado como Nitossolo Vermelho Eutroférrico (EMBRAPA, 1999). O relevo da área experimental é considerado uniforme, sendo a declividade média igual a $6 \%$.

A densidade do solo foi determinada pelo método do anel volumétrico, com auxílio de anéis de alumínio de $5 \mathrm{~cm}$ de diâmetro e $3 \mathrm{~cm}$ de altura. $\mathrm{O}$ limite superior de umidade foi considerado como sendo o conteúdo de água retido a $6 \mathrm{kPa}$ (Souza \& Reichardt, 1996).

O sistema de irrigação por aspersão utilizado para cada nível de uniformidade adotado (cenário) foi composto de cinco linhas laterais adjacentes, com cinco aspersores por linha, funcionando simultaneamente à mesma pressão, conforme Figura 3. A pressão foi ajustada atuando-se na válvula de gaveta dispostas no tubo de elevação de cada aspersor.

Os aspersores utilizados foram da marca Fabrimar, modelo A $232 \mathrm{ECO}$, bocais 5,6 x 3,2 mm. Em cada cenário funcionavam, simultaneamente, 25 aspersores, sendo suas características operacionais apresentadas na Tabela 2, destacando-se que os mesmos não funcionaram em condições recomendadas em catálogo do fabricante.

Nas linhas laterais usaram-se tubos de PVC de $50 \mathrm{~mm}$ de diâmetro. Os comprimentos das linhas laterais foram de 54, 78,78 e $102 \mathrm{~m}$, respectivamente, para os espaçamentos de $12 \mathrm{x}$ $12 \mathrm{~m} ; 18$ x $18 \mathrm{~m} ; 18$ x $24 \mathrm{~m}$ e 24 x $24 \mathrm{~m}$ entre aspersores. Esses espaçamentos entre aspersores foram denominados, de cenários, sendo o cenário 1 correspondente ao espaçamento entre aspersores de $12 \times 12 \mathrm{~m}$ e os cenário 2,3 e 4 referentes, respectivamente, aos espaçamentos de 18 x 18, 18 x 24 e 24 x 24 $\mathrm{m}$. As ligações entre os tubos e os aspersores (tubo de elevação) foram feitas com tubos de PVC de $25 \mathrm{~mm}$ de diâmetro e $0,6 \mathrm{~m}$ de comprimento e, neles, instaladas válvulas de gavetas e manômetros de "Bourdon", para controle da pressão em cada aspersor. As linhas principais constituíram-se de tubos de PVC de $75 \mathrm{~mm}$, com diferentes comprimentos em função da localização do ensaio na área experimental.

Trabalhou-se com quatro espaçamentos entre aspersores, com a finalidade de se obter altos e baixos coeficientes de uniformidade de distribuição na superfície do solo, possibilitando a comparação com coeficientes de uniformidade de umidade abaixo da superfície. Os efeitos dos diferentes níveis de uniformidade sobre as variáveis de produção e de crescimento da cultura do feijão foram também avaliados. Para a realização do estudo proposto, as variáveis foram avaliadas nas quatro amostragens em cada cenário nas mesmas épocas e utilizando-se sempre os mesmos critérios, isto é, obtendo-se dados em cada quadrícula de $9 \mathrm{~m}^{2}$. As variáveis avaliadas foram índice de área foliar (IAF), número de vagens por planta

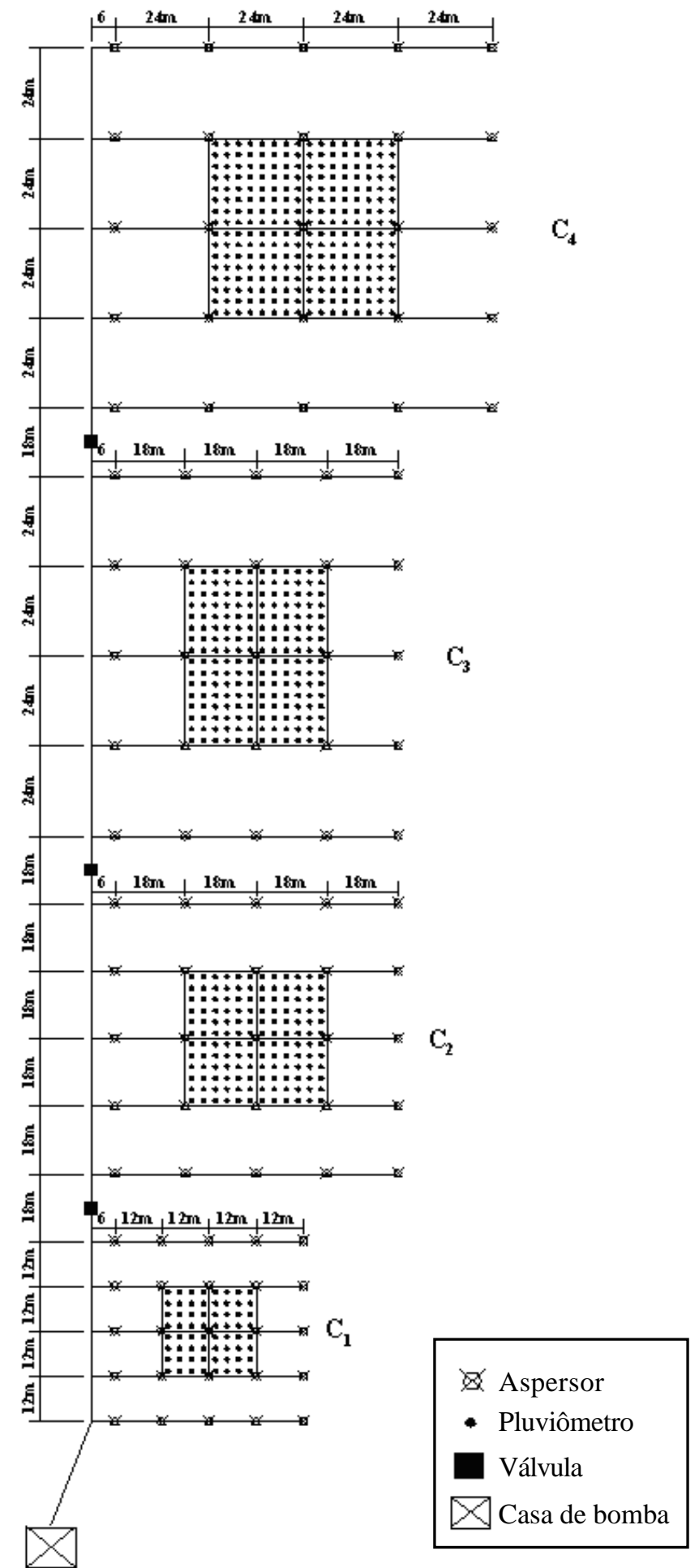

Figura 3. Esquema do experimento de campo com a cultura de feijão, mostrando os quatro cenários $\left(\mathrm{C}_{1}, \mathrm{C}_{2}, \mathrm{C}_{3}\right.$ e $\left.\mathrm{C}_{4}\right)$

Tabela 2. Características do aspersor, bocais, pressão de serviço (PS), vazão (Q.), diâmetro molhado (DM), espaçamento (E) e intensidade de aplicação (Ia)

\begin{tabular}{|c|c|c|c|c|c|}
\hline \multirow{2}{*}{$\begin{array}{c}\text { Bocais } \\
(\mathrm{mm})\end{array}$} & \multirow{2}{*}{$\begin{array}{c}\text { PS } \\
\text { (mca) }\end{array}$} & \multirow{2}{*}{$\begin{array}{c}\mathrm{Q} \\
\left(\mathrm{m}^{3} \mathrm{~h}^{-1}\right)\end{array}$} & DM & E & \multirow{2}{*}{$\begin{array}{c}\text { Ia } \\
\left(\mathrm{mm} \mathrm{h}^{-1}\right)\end{array}$} \\
\hline & & & \multicolumn{2}{|c|}{ (m) } & \\
\hline \multirow{4}{*}{$5,6 \times 3,2$} & 30 & 2,52 & 28 & $12 \times 12$ & 17,50 \\
\hline & 30 & 2,52 & 28 & $18 \times 18$ & 7,78 \\
\hline & 25 & 2,36 & 25 & $18 \times 24$ & 5,46 \\
\hline & 25 & 2,36 & 25 & $24 \times 24$ & 4,10 \\
\hline
\end{tabular}


(NV), número de grãos por vagem (NG) e massa de cem grãos (MC).

A obtenção dos dados referentes à área foliar da cultura foi feita por meio de amostragens em cinco épocas distintas, com intervalos de dez dias entre cada coleta, sendo que as mesmas ocorreram aos trigésimo, quadragésimo, qüinquagésimo, sexagésimo e setuagésimo dia após a emergência das plantas. Essas amostragens foram realizadas em todas as quadrículas de $3 \times 3 \mathrm{~m}$, colhendo-se aleatoriamente duas plantas para a obtenção das áreas foliares e posteriormente do índice de área foliar.

Para estimar a área foliar, utilizou-se o método de disco de folha de área conhecida, conforme recomendado por Magalhães (1979). Utilizando-se um perfurador de folhas de $3,3 \mathrm{~cm}$ de diâmetro, a fim de relacionar o peso seco da área conhecida do disco com o peso seco de todas as folhas de cada planta. Estes discos de folhas, em maior número possível e obtidos de várias partes das folhas, foram acondicionados em sacos de papel e levados à estufa de aeração forçada, para secagem até peso constante. O restante das folhas usadas para a retirada dos discos e as não usadas foram acondicionadas em outro saco de papel e levadas à estufa para secagem. Estimou-se a área dessas folhas a partir das relações entre matéria seca dos discos, área total dos discos (soma das áreas de todos os discos de uma mesma planta) e a matéria seca total das folhas amostradas (folhas usadas, folhas não usadas e dos discos). Para determinar o IAF, dividiu-se a área foliar da planta pela área de solo disponível à mesma.

Para a obtenção do número de vagens por planta, em um período que antecedeu a colheita, foi feita a contagem em quatro plantas escolhidas aleatoriamente dentro de cada quadrícula e posteriormente calculou-se a média do número de vagens por planta.

O número de grãos por vagem foi obtido também, para cada quadrícula, utilizando-se todas as vagens das quatro plantas nas quais obteve-se o número de vagem por planta. Posteriormente foi calculada a média dos valores obtidos.

Para a obtenção da massa de cem grãos foram separados, aleatoriamente, cem grãos das mesmas plantas de cada quadrícula, das quais obteve-se o número de vagem e também o número de grãos por vagem. Após terem sido separados, foram pesados em balança de precisão e padronizando-se as umidades para $13 \%$, obteve-se a massa de cem grãos em gramas.

As irrigações foram realizadas tendo-se como base a média das leituras de tensiômetros instalados nas parcelas experimentais, nas profundidades de 0,20 e $0,40 \mathrm{~m}$ utilizando-se, como limite, os valores de umidade nas tensões de 0,05 MPa. Em todos os cenários aplicou-se mesma lâmina bruta de água em todas as irrigações, igual a $12 \mathrm{~mm}$; conseqüentemente foram necessários diferentes tempos de irrigação para cada cenário.

Para a obtenção dos dados necessários aos cálculos dos parâmetros estatísticos que caracterizam a distribuição de água do sistema de irrigação, foram medidas as precipitações com o uso de pluviômetros dispostos em malhas de 3 x 3 m, nas áreas compreendidas entre os nove aspersores centrais, nos quatro cenários utilizados. Para cada um dos cenários foram realizadas quatro amostragens, onde em cada uma delas considerou-se a área compreendida entre quatro aspersores.
A obtenção dos dados de uniformidade e eficiência de aplicação foi feita em todas as irrigações, mas foram utilizados dados referentes a quinze irrigações apenas, uma vez que ocorreram chuvas após as demais.

As condições climáticas reinantes durante os ensaios realizados, válidas para os quatro cenários, foram relativamente estáveis, não sendo possível se detectar seus efeitos sobre os coeficientes de uniformidade obtidos. $\mathrm{O}$ valor médio da velocidade do vento foi igual a $0,62 \mathrm{~m} \mathrm{~s}^{-1}$, com coeficiente de variação $(\mathrm{CV})$ de $8,0 \%$. A umidade relativa média foi de $58 \%$, com CV de $16,4 \%$ e a temperatura média foi de $20,6^{\circ} \mathrm{C}$, com CV de $18,6 \%$. Com base nesses valores, pode-se verificar que o vento, fator que mais tende a influenciar o padrão de irrigação, apresentou valores baixos de velocidade, não comprometendo a qualidade da irrigação realizada. Os outros dois fatores, na medida em que não variaram muito entre irrigações, tenderam a influenciá-las de modo semelhante. A evaporação, medida em oito coletores dispostos próximos à área experimental, foi nula. Este fato pode ser explicado em função dos horários nos quais foram realizadas as irrigações, ou seja, no amanhecer dos dias, quando a incidência de ventos é menor na região.

Quanto às precipitações ocorridas durante o ciclo da cultura (23/03 a 22/06) totalizaram $208,7 \mathrm{~mm}$, sendo considerado um índice alto para a região em tal período. A época e a magnitude das lâminas de irrigação e de precipitação podem ser vistas na Figura 4.

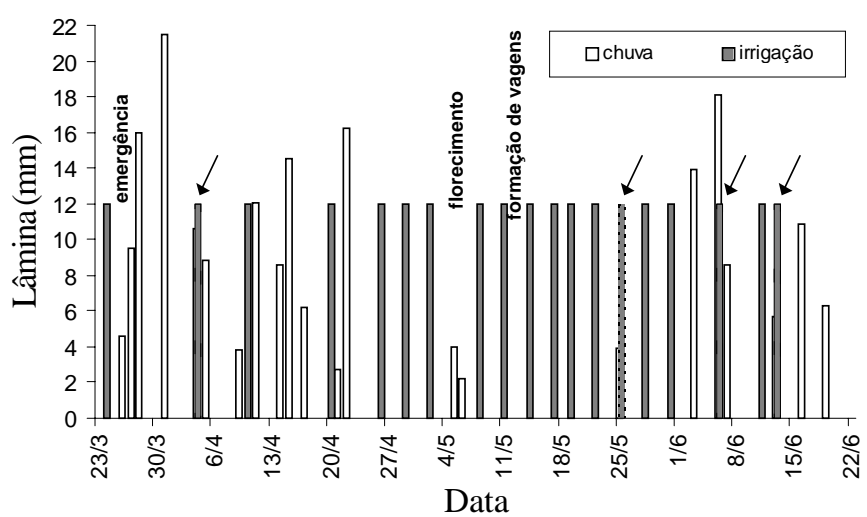

Figura 4. Lâminas de água aplicadas via irrigação e decorrentes de chuva, durante o ciclo da cultura. As quatro irrigações em destaque, marcadas por uma seta, foram seguidas de chuva

Em decorrência do alto índice pluviométrico, foram realizadas somente dezenove irrigações durante todo o ciclo da cultura, somando-se $228 \mathrm{~mm}$, das quais foram utilizadas para análise quinze delas, sendo que, após quatro irrigações, houve interferências de chuvas nos dados, como pode ser observado na Figura 4.

\section{RESULTADOS E DISCUSSÃO}

\section{Ensaio com milho}

Os dados de produtividade da cultura do milho versus lâmina de água foram plotados na Figura 5A, para os tratamentos com aplicação com alta uniformidade e para os 
tratamentos com baixa uniformidade de aplicação de água, na Figura 5B. A produtividade da cultura mostrou a mesma tendência de dispersão dos valores que a observada para os valores de IAF (Figuras 6A e B).
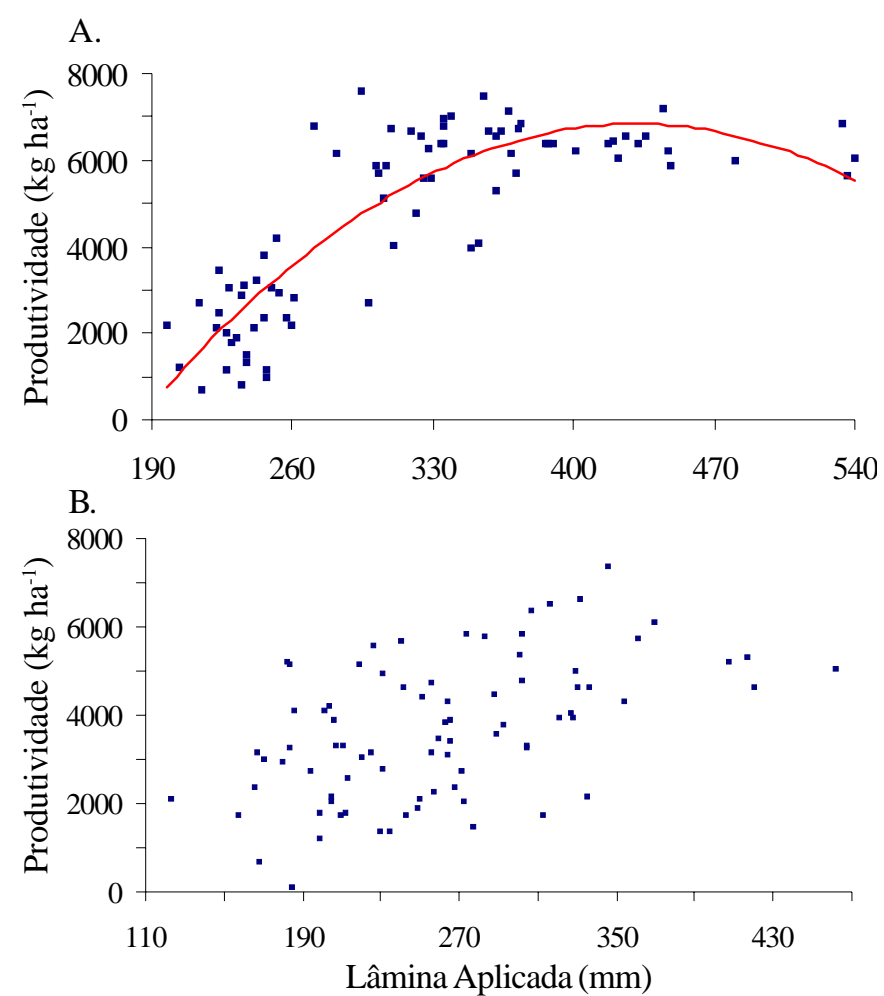

Figura 5. Produtividade da cultura do milho em função da lâmina de água aplicada para os tratamentos com alta (A) e baixa (B) uniformidade de aplicação d'água

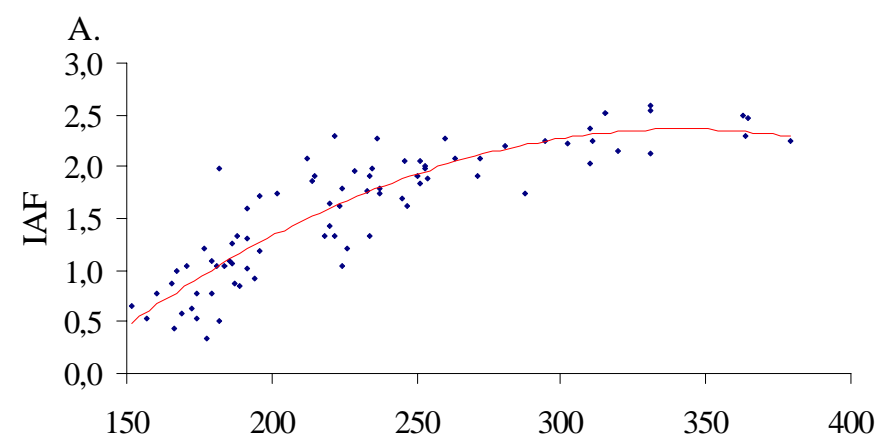

B.

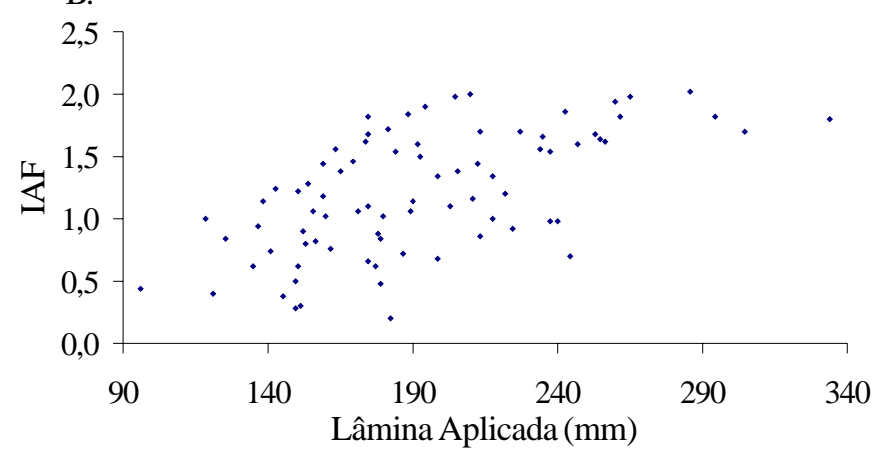

Figura 6. Índice de área foliar da cultura do milho em função da lâmina de água, para os tratamentos com alta (A) e baixa (B) uniformidade de aplicação d'água
Analisando-se a Figura 5A, observa-se que o aumento da lâmina d'água aplicada diminuiu as discrepâncias dos valores das produtividades, em que, para menores lâminas d'água, há maior variabilidade na produtividade. Observou-se, também, tendência de diminuição da produtividade com o aumento da lâmina de água aplicada.

Ajustou-se um modelo para 81 dados coletados de produtividade da cultura do milho, dados apresentados na Figura 5. Os coeficientes do modelo apresentado na equação 2, para os valores de CUC não foram significativos a nível de $5 \%$ pelo teste $\mathrm{t}$, somente os coeficientes para lâmina d'água, os resultados diferem dos encontrados por Mateos et al. (1997).

$$
\begin{gathered}
\mathrm{Y}=-118.961+96,48 \mathrm{~L}-0,1104 \mathrm{~L}^{2}+ \\
2.544,96 \mathrm{CUC}-15,41 \mathrm{CUC}^{2} \\
\mathrm{R}^{2}=0,85
\end{gathered}
$$

O modelo foi novamente ajustado, considerando apenas lâmina d'água como variável independente:

$$
\begin{gathered}
\mathrm{Y}=-13.917+96,38 \mathrm{~L}-0,1118 \mathrm{~L}^{2} \\
\mathrm{R}^{2}=0,75
\end{gathered}
$$

em que:

Y - produtividade da cultura, em $\mathrm{kg} \mathrm{ha}^{-1}$

L - lâmina d'água, em mm.

Os valores de produtividade nos tratamentos com baixa uniformidade apresentaram alta dispersão para as lâminas d'água de mesmo valor ou de valores próximos aos da aplicação de água para este tratamento. A dispersão dos valores da produtividade (Figura 5B), fez com que o ajuste da equação de regressão para os dados apresentasse um coeficiente de determinação muito baixo, de 0,26.

O modelo ajustado foi:

$$
\begin{gathered}
\mathrm{Y}=-380.090+22,15 \mathrm{~L}-0,01795 \mathrm{~L}^{2}+ \\
11.031,2 \mathrm{CUC}-80,14 \mathrm{CUC}^{2}
\end{gathered}
$$

Os coeficientes do modelo não foram significativos a $5 \%$ pelo teste $\mathrm{t}$, para a lâmina d'água, mas foram significativos para o coeficiente de uniformidade de aplicação. Os valores de CUC variaram de 65 a 72\%, enquanto a lâmina de água variou de 157 a 462 mm, como pode ser observado na Figura 5B. Situação esta diferente da encontrada para alta uniformidade de aplicação de água.

São encontradas, para pequenas diferenças nas lâminas d'água, variações nos valores de IAF. Esta discrepância diminui com o aumento da lâmina de água aplicada, pois tal aumento não proporciona um significativo incremento no IAF, com tendência para estabilização em relação ao aumento da lâmina de água (Figura 6A). 
O modelo ajustado para o IAF em função da lâmina de água e coeficiente de uniformidade de Christiansen está apresentado na equação 5. Os coeficientes da regressão foram significativos pelo teste $\mathrm{t}$ a nível de $5 \%$ de probabilidade.

$$
\begin{gathered}
\text { IAF }=-138,5+0,0242 \mathrm{~L}-0,000026 \mathrm{~L}^{2}+ \\
0,033 \mathrm{CUC}-0,0202 \mathrm{CUC}^{2}
\end{gathered}
$$

em que:

$$
\mathrm{R}^{2}=0,85
$$

IAF - índice de área foliar da cultura, em $\mathrm{m}^{2} \mathrm{~m}^{-2}$

L - lâmina d'água, em mm

Os dados das lâminas de água e do IAF para os tratamentos com baixa uniformidade de aplicação foram plotados na Figura 6B. Realizou-se a análise de regressão, mas os modelos ajustados apresentaram baixo coeficiente de determinação de 0,36, em razão da dispersão acentuada dos valores:

$$
\begin{gathered}
\mathrm{IAF}=122,394-0,00797892 \mathrm{~L}+-0,00006024 \mathrm{~L}^{2}+ \\
3,55025 \mathrm{CUC}-0,02511 \mathrm{CUC}^{2}
\end{gathered}
$$

Os coeficientes da regressão foram significativos ao nível de $5 \%$ pelo teste $\mathrm{t}$, apenas o coeficiente quadrático da lâmina de água não foi significativo. Não ajustou-se outro modelo razão do baixo coeficiente de determinação encontrado, pois o modelo não descreve adequadamente os dados observados.

\section{Ensaio com feijão}

Os dados de produtividade da cultura do feijão versus lâmina d'água, foram plotados na Figura 7A, para os tratamentos com aplicação com alta uniformidade, e para os tratamentos com baixa uniformidade de aplicação de água, na Figura 7B. A produtividade
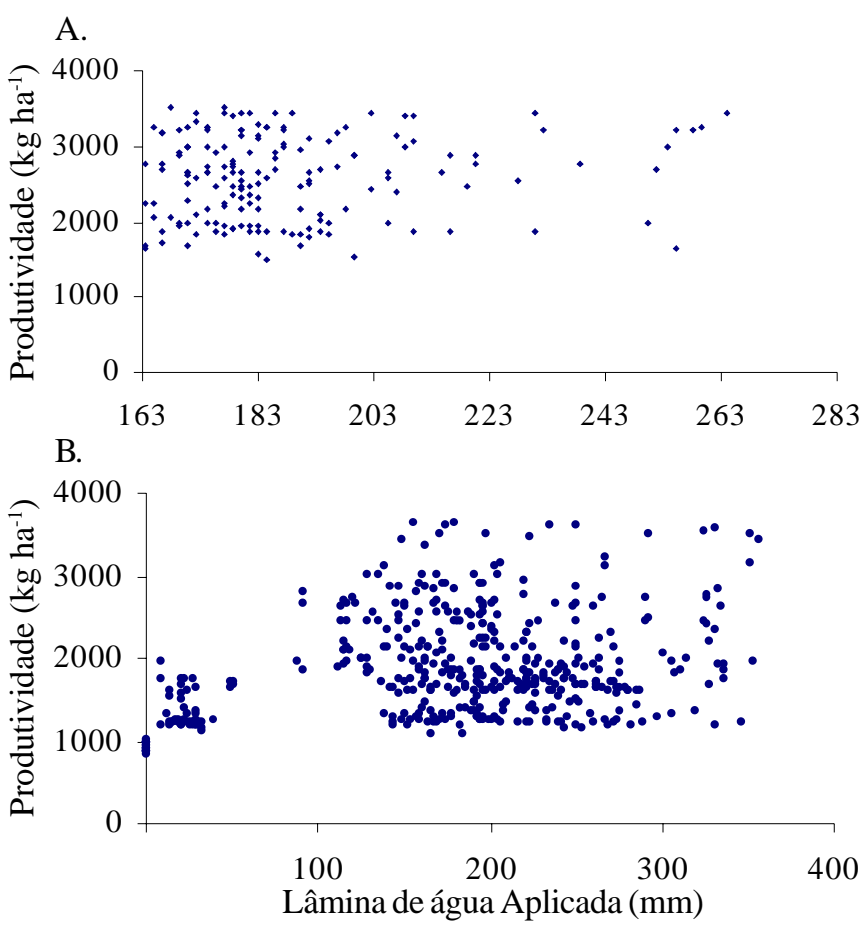

Figura 7. Produtividade da cultura do feijão para tratamentos com alta (A) e baixa (B) uniformidade de aplicação d'água da cultura mostrou a mesma tendência de dispersão dos valores que a observada para os valores de IAF (Figuras 8A e B).

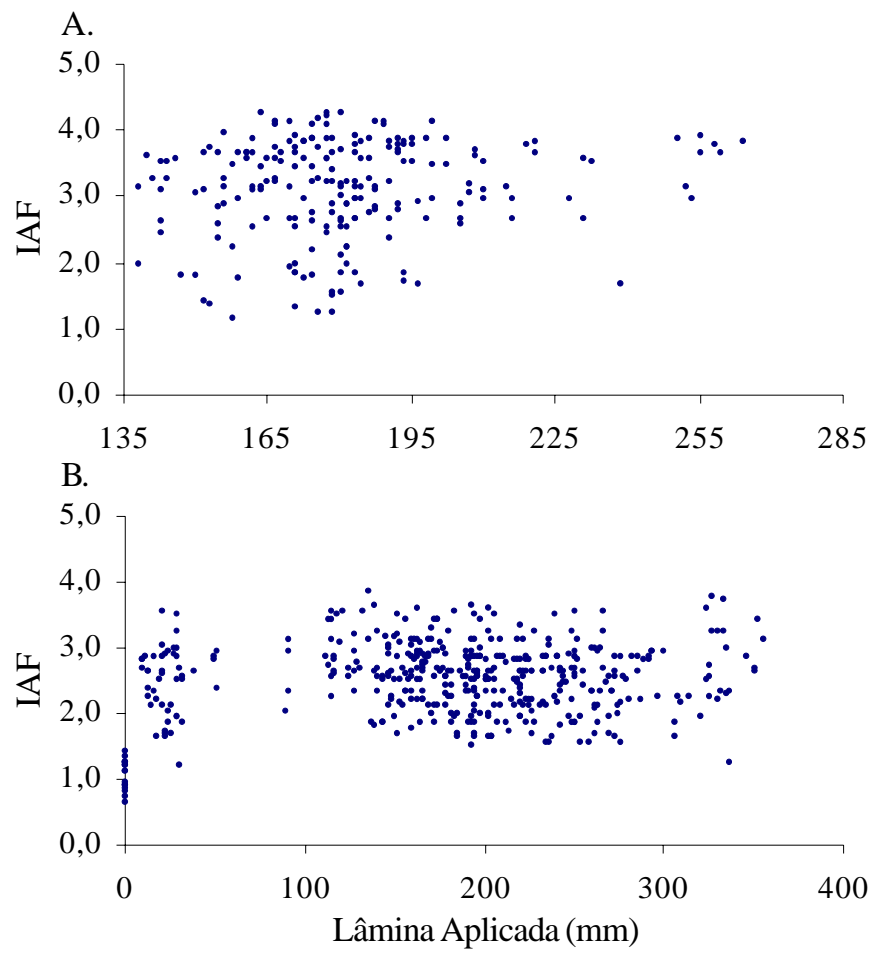

Figura 8. Índice de área foliar da cultura do feijão para tratamentos com alta (A) e baixa (B) uniformidade de aplicação d'água

Os valores de produtividade nos tratamentos com baixa uniformidade apresentaram alta dispersão para as lâminas de água de mesmo valor ou de valores próximos ao da aplicação de água para estes tratamentos. Para os tratamentos com aplicação de água de alta uniformidade (CUC > 86\%) os valores da produtividade em função da lâmina de água, apresentaram comportamento diferente, quando comparado ao da cultura do milho (Figura 5A). Para a cultura do milho foi possível ajustarse uma equação de regressão, enquanto para a cultura do feijão, em razão da dispersão dos dados, não é possível se ajustar uma equação de regressão da produtividade em função da lâmina de água, sendo que a produtividade não é função apenas da lâmina d'água aplicada mas, também, de outros fatores; isto impossibilita que se determine um comportamento da lâmina de água versus produtividade para diferentes uniformidades de aplicação de água para introduzir este efeito em modelos de simulação de crescimento de culturas. Em razão desta dificuldade é que Pang (1997) utilizou uma metodologia proposta por Letey et al. (1984) para simular a influência da uniformidade na produtividade das culturas.

As produtividades média, máxima e mínima obtidas para os tratamentos com alta uniformidade foram 2.628, 3.521 e 1.503 $\mathrm{kg} \mathrm{ha}^{-1}$, respectivamente (Figura 7A).

A distribuição da precipitação ao longo do ciclo da cultura possibilitou obter-se uma produtividade média de $935 \mathrm{~kg} \mathrm{ha}^{-1}$ e, para a lâmina de água aplicada de $23,4 \mathrm{~mm}$, a produtividade foi de $1.239 \mathrm{~kg} \mathrm{ha}^{-1}$ para os tratamentos com baixa uniformidade. Isto ocorreu em razão de que antes do florescimento da cultura não ocorreram precipitações e a aplicação da lâmina de água possibilitou o incremento na produtividade. Como pode ser 
observado na Figura 7B, a produtividade média para esta condição foi de $1.896 \mathrm{~kg} \mathrm{ha}^{-1} \mathrm{e}$ a máxima e mínima foram de 835 e $3.655 \mathrm{~kg} \mathrm{ha}^{-1}$, respectivamente. $\mathrm{O}$ mesmo comportamento ocorreu para o índice de área foliar (Figura 8B).

A equação de regressão ajustada para os tratamentos com alta uniformidade foi:

$$
\begin{aligned}
\mathrm{Y}= & -162779+102,76 \mathrm{~L}-0,0250 \mathrm{~L}^{2}+ \\
& 491,10 \mathrm{CUC}-3,00 \mathrm{CUC}^{2}
\end{aligned}
$$

$$
\mathbf{R}^{2}=0,11
$$

Os coeficientes da regressão não foram significativos ao nível de 5\% pelo teste t. O coeficiente de determinação foi muito baixo.

A equação ajustada para os tratamentos com baixa uniformidade foi:

$$
\begin{array}{r}
\mathrm{Y}= \\
-408562+4,12 \mathrm{~L}-0,064 \mathrm{~L}^{2}+ \\
1.399,93 \mathrm{CUC}-12,28 \mathrm{CUC}^{2}
\end{array}
$$

$$
\mathrm{R}^{2}=0,59
$$

Os coeficientes de regressão para lâmina de água foram significativos em nível de 5\% pelo teste $t$, mas os coeficientes para uniformidade não apresentaram significância.

Para o IAF foram ajustadas equações de regressão para a alta e baixa uniformidades. Para alta uniformidade de aplicação de água obteve-se a seguinte equação:

$$
\begin{gathered}
\mathrm{IAF}=-31,22+0,015 \mathrm{~L}-0,0005 \mathrm{~L}^{2}+ \\
0,76 \mathrm{CUC}-0,411 \mathrm{CUC}^{2}
\end{gathered}
$$

$$
\mathrm{R}^{2}=0,20
$$

Os coeficientes da regressão não foram significativos em nível de $5 \%$ pelo teste $\mathrm{t}$, tanto para alta como para baixa uniformidade, obteve-se a seguinte equação:

$$
\begin{gathered}
\mathrm{IAF}=-35,4+0,0034 \mathrm{~L}-0,0000064 \mathrm{~L}^{2}+ \\
1,16 \mathrm{CUC}-0,088 \mathrm{CUC}^{2} \\
\mathrm{R}^{2}=0,26 \\
\text { CONCLUSÕES }
\end{gathered}
$$

\section{CONCLUSÕES}

Ajustou-se uma equação de regressão para os valores da produtividade da cultura do milho em função da lâmina de água, para os tratamentos com alta uniformidade, enquanto para os de baixa uniformidade e para a cultura do feijão não foi possível ajuste, obtendo-se baixos valores de $\mathrm{R}^{2}$. É impossível a incorporação do efeito da uniformidade de aplicação nos modelos de simulação de crescimento de culturas.

\section{LITERATURA CITADA}

Bernardo, S. Manual de irrigação. 6.ed.Viçosa: Imprensa Universitária, 1995.657p.

Boote, K.J.; Jones, J.W.; Pickering, N. B. Potential uses and limitations of crop models. Agronomy Journal, Madison, v.88, p.704-716, 1996

Clemens, A.J. Method for analyzing field scale surface irrigation uniformity. Journal of Irrigation and Drainage Division of ASCE, New York, n.IR1, p.74-88, 1988.

Duke, H.R.; Heermann, D.F.; Dawson, L.J. Appropriate depths of aplication for scheduling center pivot irrigations. Transactions. of the ASAE, St. Joseph, v.35, p.1457-1464, 1992.

EMBRAPA - Empresa Brasileira de Pesquisa Agropecuária. Sistema brasileiro de classificação de solos. Centro Nacional de Pesquisa em Solos. Rio de Janeiro. 1999. 412p.

Howell, D.T. Nonuniformity and sprinkler application efficiency. Journal of Irrigation and Drainage Division of ASCE, New York, n.IR3, p.55-67, 1964.

Kiniry, J.R.; Willians, J.R.; Vanderlip, R.L.; Atwood, J.D.; Reicosky, D.C.; Mulliken, J.; Cox, W. J.; Mascani Jr., H. J.; Hollinger, S.E.; Wiebold, W. J. Evalution of two maize models for nine U. S. locations. Agronomy Journal, Madison, v.89, p.421-426, 1997.

Letey, J.; Vaux, H.J.; Feinerman, E. Optimum crop water as affected by uniformity of water infiltration. Agronomy Journal, Madison, v.76, p.435-441, 1984.

$\mathrm{Li}$, J.S. Modeling crop yield as affected by uniformity of sprinkler system. Agricultural Water Management, Amesterdam, v.38, p.135-146, 1998.

Magalhães, A.C.N. Análise quantitativa do crescimento. In: Fisiologia Vegetal. São Paulo: Editoras EPU e EDUSP, 1979. v.1, p.331-350.

Mantovani, E.C.; Villalobos, F.J.; Orgaz, F.; Fereres, E. Modeling the effects of sprinkler irrigation uniformity in crop yield. Agricultural Water Management, Amesterdam, v.27, p.243257, 1995.

Mateos, L.; Mantovani, E.C.; Villalobos, F.J. Cotton response to non-uniformity of convencional sprinkler irrigation. Irrigation Science, Berlin, v.17, p.47-52, 1997.

Pang, X.P.; Letey, J.; Wu, L. Yield and nitrogen uptake prediction by CERES-Maize model under semiarid conditions. Soil Science Society of America Journal, Madison, v.61, p.254-256, 1997.

Rezende, R.; Frizzone, J.A.; Goncalves, A.C.A.; Freitas, P.S.L. Influência do espaçamento entre aspersores na uniformidade de distribuição de água acima e abaixo da superfície do solo. Revista Brasileira de Engenharia Agrícola e Ambiental, Campina Grande, v.2, p.247-352, 1998.

Seginer, I. A note on the economic significance of uniform water application. Irrigation Science, Berlin, v.19, p.19-25, 1978.

Souza, L.D.; Reichardt, K. Estimativa da capacidade. Revista Brasileira de Ciência do Solo, Campinas, v.20, p.183-189,1996.

Walker, W.R. Explicit sprinkler irrigation uniformity: efficiency model. Journal of Irrigation and Drainage Division of ASCE, New York, n.IR2, p129-136, 1979.

von Bermuth, R.D. Uniformity design criteria under limited water. Transactions of the ASAE, St. Joseph, v.26, n.5, p.1418$1421,1983$. 